\title{
REPRESENTAÇÃO NA PERSPECTIVA FENOMENOLÓGICA SOBRE O PENSAR A MORTE E O MORRER
}

\section{REPRESENTATION IN THE PHENOMENOLOGICAL PERSPECTIVE ON THINKING ABOUT DEATH AND DYING}

\author{
SANTANA ${ }^{1}$, Francileide; TOLOVI ${ }^{2}$, Carlos Alberto
}

Recebido em: 21/09/2017; Aceito: 02/11/2017; Publicado: 01/12/2017.

\begin{abstract}
RESUMO
Este artigo tem como objetivo compreender e descrever como o fenômeno da morte e do morrer está representado na percepção das pessoas na condição de finitude. Pretende também analisar como essa representação se manifesta no comportamento durante o fato acontecido, estando essa percepção na ordem dos sentidos representativos que motiva o lidar com a morte. E por fim, descrever os fenômenos dos rituais funerários e a simbologia presente nesse contexto fúnebre. A pesquisa esteve voltada na perspectiva de uma metodologia de campo, de observação participante exploratória, onde apenas a pesquisadora coletou dados sobre como se manifestaram à percepção da morte. Justifica-se, pois, pela relevância do tema e seriedade que é falar sobre a finitude do humano. Conclui-se que o mais significativo dessa pesquisa são os pressupostos que apresentou em volta da mistificação e fenômeno da morte e o morrer para as pessoas que contribuíram no estudo e na observação.

PALAVRAS-CHAVES: Enfrentamento da doença. Finitude. Morte e morrer. Sofrimento Psíquico.
\end{abstract}

\section{ABSTRACT}

This article aims to understand and describe the phenomenon of death and dying is represented in people's perceptions on the condition of finitude. Also intends to analyze how this representation is manifested in behavior happened during the fact being that perception in order representative senses that motivates deal with death. Finally, describe the phenomena of funeral rites and the funeral in this context symbology. The research has focused on the prospect of a field methodology, exploratory participant observation, where only the researcher collected data expressed as the perception of death. Is justified, because the topic relevance and seriousness that is talking about human finitude. We conclude that the most significant of this research are the assumptions presented around the mystification and the phenomenon of death and dying to the people who contributed in study and observation.

KEYWORDS: Fighting the disease; Finitude, Death and dying, Psychic Suffering.

\footnotetext{
1 Graduada em Psicologia pela Faculdade de Ciências aplicadas Dr. Leão Sampaio francileidesantana@yahoo.com.br

${ }^{2}$ Graduado em Filosofia, Mestre e Doutorando em Ciência da Religião-ctolovi@yahoo.com.br
} 


\section{INTRODUÇÃO}

Como seres de todas as condições de vida na biosfera, o ser humano é aquele que tem o privilégio da comunicação de sua raça, possuindo plena capacidade de discernimento e dotado dos sentidos como norteadores de suas escolhas. As sensações, percepções, pensamentos nos permitem a todo o momento um comportamento para novas posturas diante dos desafios, permitindo assim várias mudanças no cotidiano.

Contextualizar sobre a vida é algo pelo qual podemos compreender a trajetória como ser humano. No entanto, o ciclo vital compõe-se de processos evolutivos que vai desde a concepção, nascimento, desenvolvimento, reprodução e consequente morte, ou seja, a finitude. Todos esses fenômenos são inerentes à vida cotidiana. Porém, para alguns indivíduos esses processos podem ser percebidos como fatores comuns, a respeito dos quais falam abertamente e não incomodam. Já outros indivíduos sequer cogitam a ideia de morte, não reagem e nem admitem chegar a finitude.

A reação perceptiva diante do que não sabemos ou conhecemos causa estranheza e muito nos faz refletir sobre como podemos ou devemos ocultar tal pensamento. Suscitar sobre o tema morte e morrer requer seriedade, ética e respeito diante dos valores pessoais, familiares e culturais. $\mathrm{O}$ indivíduo se projeta diante da vida no antes, durante e depois. Por conseguinte, a angústia de deparar-se com o sofrimento que se apresenta no processo do adoecimento e tantas outras etapas que evoluem em buscar restabelecimento da saúde e, quando isso não é possível haverá a consequente morte.

Diante do sofrimento da doença orgânica o indivíduo não deixa de ter sua subjetividade. Pelo contrário, ela está atuando a plena capacidade e até mesmo mais atuante que antes. Somente num estágio como o enfrentamento da doença é que o indivíduo se dá conta das etapas da vida deixaram de ser valorizadas. No entanto, não havia uma patologia. Esse questionamento está dentro da normalidade que o indivíduo vivencia, pois o coloca diante de sua real condição de pulsão de vida e morte e as instâncias psíquicas estão plenamente em conflito sobre tal questão. Enquanto a atenção the é dada, pela escuta, o indivíduo deixa fluir seu apelo à vida enquanto tem consciência que pode ser tarde demais.

Uma vez que o fim está próximo à capacidade de contingência nesse conflito entre viver e o morrer pode ser suplementado por uma força incomum diante da fragilidade humana. Para alguns indivíduos poderá ocorrer uma nova representação em simbolizar uma forma mais elaborada e compreendida por não haver como reverter à situação. Para outros não há espaço para cogitar ou vivenciar e, assim chegar a sua finitude.

O objetivo principal da pesquisa consiste em compreender como o fenômeno da morte e do morrer está representado na percepção das pessoas na condição de finitude, como também analisar de que forma essa representação se manifesta no comportamento durante o fato acontecido. Perceber os sentidos representativos que motiva o "lidar com a morte" de uma pessoa que morreu e, por fim, descrever os fenômenos dos rituais funerários e as simbologias presentes no contexto.

A pesquisa foi elaborada a partir de uma metodologia de campo como foco na observação participante, cabendo coletar dados sobre a manifestação do comportamento das pessoas em relação à percepção da morte. "Consiste numa pesquisa qualitativa exploratória onde o pesquisador consegue perceber as possibilidades de uma aproximação com aquilo que deseja conhecer e estudar, partindo e adquirindo conhecimento da realidade que se faz presente". (NETO, 1994, p. 51).

Dentro do contexto amplo sobre o tema, de 
vivência diante do fato, a pesquisa utiliza-se da observação frente aos acontecimentos, ou seja, in loco. Os objetivos alcançados faz-se necessário a vivência dos fenômenos que norteiam a representação da morte e do morrer a que se propõe.

Os ritos dos funerais - sejam domiciliares ou em espaços especializados para esse fim - e o tempo de preparação para o velório do indivíduo acometido pela morte é um fator preponderante para a confirmação do que se busca nessa pesquisa.

Justifica-se, pois, pela relevância do tema e seriedade que é falar sobre a finitude do ser humano. Notadamente o mais significativo para a pesquisadora são os pressupostos que há em volta da mistificação da morte e o morrer para as pessoas, notadamente esses sujeitos contribuíram para o estudo e observação. A cerca de representação da morte nos tempos atuais, torna-se escasso a busca em suscitar a temática e, motivada pela curiosidade, a pesquisadora instiga na sua busca elementos que são representativos para a cultura de morte de pessoas. Neste contexto, torna-se necessário uma abordagem mais superficial da pesquisa em nortear aspectos apenas da observação dos fenômenos, embora haja muitos subsídios para serem explorados em outra pesquisa futura.

Tornar esses fenômenos discutidos no resultado da pesquisa no contexto da representação da morte permite ampliar novo viés para outras representações no alcance do objetivo primeiro. Inicialmente pensou-se em falar do sentimento propriamente dito, comportamento manifesto, porém, a levando-se em conta ética em abordar tão explicitamente o fenômeno da morte e tornar o sofrimento demorado para os familiares optou-se pela pesquisa participante. Nesse contexto torna-se fundamental para a pesquisadora questionar: Como compreender e analisar o fenômeno da morte e do morrer na concepção de finitude das pessoas em épocas diferente?

\section{REPRESENTAÇÃO SOBRE O PENSAR A MORTE E O MORRER}

\section{Sobre o temor da morte}

A morte suscita um questionamento e traz muitas questões acerca do enfrentamento da finitude. A morte é uma consequência natural da vida, faz parte do ciclo vital que todos os seres enfrentam. Para a condição humana é certo que não se pode escapar dessa etapa do ciclo vital que se fecha. Para algumas pessoas o fato de apenas pensar na morte já causa desconforto, luta, rejeição ou fuga. Para que o indivíduo possa assimilar entre sua real situação com um fato novo que lhe tira a plenitude é desconfortante e causa temor, medo e mudança de comportamento.

Do ponto de vista psiquiátrico, isto é, bastante compreensível e talvez explique melhor pela noção básica de que, em nosso inconsciente, a morte nunca é possível quando se trata de nós mesmos. É inconcebível para o inconsciente imaginar um fim real para nossa vida na terra e, se a vida tem um fim, este será sempre atribuído a uma intervenção maligna fora do nosso alcance (KÜBLER-ROSS, 1996, p. 14).

Kübler-Ross (1996), fez um trabalho de pesquisa no Departamento de Psiquiatria do Hospital Billings da Universidade de Chicago com vítimas de câncer, e ela percebeu no seu estudo que, a instância psíquica do ser humano com relação à morte faz referência que a ideia sobre finitude não há como vislumbrar a vida como fim, ou seja, não considera como acabada a vida pulsante. Ela faz aporte que é algo inerente que não nos pertence, mas que está presente a todo o momento. Associar uma vida que usufruímos em sua plenitude e em seguida nos depararmos com algo que nos tira o 
sentido da vida, causa estranheza e repúdio. Assimilar e aceitar essa verdade são algo que desmonta tudo que foi construído diante de nossa vivência humana.

A necessidade humana de se explicar, de saber sua origem e de tentar desvendar qual será o seu destino após a morte faz com que seja buscado e teorizado sem nenhum parâmetro de aceitação em contradições a tais princípios e buscas (CAMOM, 2008, p. 04).

A autora Kübler-Ross (1996) fala nesse capítulo sobre diversas formas de temores acerca da morte, citando exemplos de como chega essa realidade para as pessoas. Um fato curioso que chamou atenção foi de um senhor fazendeiro que sofreu uma queda e pediu para morrer em casa. É um exemplo bastante claro de aceitação, pois a atitude diante do fato põe a pessoa acerca do seu fim, dando-lhe a oportunidade de distribuir entre os seus a partilha de bens e responsabilidades. Com isso, ele "pode" morrer em paz. É curioso porque de imediato decidiu dar as ordens, pois seu fim chegou e não queria "partir" sem que tivesse cumprido sua missão. Esse fato foi vivenciado pela autora quando ainda era criança e não foi esquecido. Já na atualidade não se tem mais esse ritual.

Morrer se torna um ato solitário e impessoal porque o paciente não raro é removido de seu ambiente familiar e levado às pressas para sua sala de emergência. Qualquer um que tenha estado muito doente e necessitado de repouso e conforto se lembrará de ter sido posto numa maca sob o som estridente da sirene, e da corrida desenfreada, até de abrirem as portas do hospital (KÜBLER-ROSS, 1996, p. 20).

Estar doente significa já um estado de vulnerabilidade, e quando não havendo um tratamento mais humanizado o indivíduo se vê a sós diante do seu sofrimento e enfrentamento de sua patologia. No tocante a gravidade no caso de pacientes do departamento de psiquiatria o qual trabalhou. Pela autora, os pacientes entrevistados no hospital e os estados de saúde com agravamento e alguns em estado terminal, só lhes resta o conformismo e abandono, ou seja, já não têm recurso para a cura, assim perde-se sua identidade e já não é concedido o direito de opinar.

Nesse processo o paciente está sofrendo mais pelo que ainda pode ser feito por ele, e o hospital está ali exatamente para essa função: o alívio da dor orgânica. O sofrimento psíquico, esse não poderá ser mensurado. É o momento da vivência mais expressiva pelo paciente, qual sua postura frente à doença e como ele lida com esse temor de morte. Essa questão é permeada de um imenso anseio de luta. Para alguns pode ser mais aceito, para outros paciente pode ser extremamente sofrível e inaceitável.

\section{Atitudes diante da morte e do morrer}

Trazendo para essa vertente pode-se perceber o quanto ainda é um tabu se falar abertamente sobre morte e quais contribuições pode surtir. É um tanto pesado falar sobre a contribuição da morte. Contudo, embora com todo o respeito que o assunto emerge, é possível sim fazer várias leituras acerca do pensar a morte e o morrer. As pessoas estão mais habituadas a planejamentos futuros, planos em longo prazo para uma velhice tranquila, vários métodos para prolongar a juventude.

Estamos no convívio social da medicina estética corretiva, preventiva e curativa, mas deixam-se de lado alguns aspectos subjetivos como a nossa finitude. Não existe uma cultura onde se trabalha nosso deixar de existir. É projeção perpetuar nossos genes para a posteridade, e, isso se faz através dos descendentes, mas que no fundo oculta-se o medo da morte. A ciência moderna já 
usa técnicas avançadas como a clonagem, implante de células tronco para prevenção e cura de doenças e até retardar a morte.

Notadamente o termo usado nesse livro (Sobre a morte e o morrer), a morte dá uma visão global da finitude. Contudo, o fato é que não acontece apenas pelo adoecimento, mas pelas circunstâncias que se dão. Vejamos na problemática de ataques suicidas planejados por grupos e facções islâmicas pelo mundo a fora. Essa forma de aniquilamento é um fato em si, tirando a vida de pessoas que não deveriam ter morrido naquela circunstância. Outro fato bastante comum são as guerras onde milhares de combatentes perdem suas vidas, movidos por uma ideologia da pátria a que serviu.

\begin{abstract}
"Contudo", podemos aceitar a morte do próximo, e as notícias do número dos que morrem nas guerras, nas batalhas e nas autoestradas só confirmam a crença inconsciente em nossa imortalidade, fazendo com que - no mais recôndito do nosso inconsciente - nos alegremos com um "ainda bem que não fui eu" (KÜBLER-ROSS, 1996, p. 26).
\end{abstract}

Uma vez que não se pode fugir do fato em si, existe a luta pela rejeição ao concreto. Ocorre comportamento de burlar as frustrações a outros desafios, tentando suprimir esse medo que aterroriza e o indivíduo fica na tensão por não querer aceitar o fato. Esses acontecimentos podem ocorrer por situações vividas anteriormente e apontam no contexto atual ao não saber lidar com uma certeza, trazendo consequências desastrosas Esses eventos se referem a comportamentos violentos arraigados pela cultura social e urbana, nesse sentido, há uma maior probabilidade de despertar nele um estado de violência desenfreada, ocorrendo inúmeras e crescentes incapacidades de não se perceber ou ainda não administrar as emoções e adversidades. O indivíduo torna-se incapaz de ter um raciocínio lógico, ou seja, sua inteligência emocional se compromete e inconscientemente cresce o número estatístico da violência.

Nesse contexto pode-se perceber o papel da religião e sua função na vida dos indivíduos; em tempos não muito distantes, tinham atitudes e condutas um tanto arraigadas e incondicionadas à fé em Deus. Com isso acreditavam que ao morrer simbolizava certeza que obteriam uma vida futura, aliviando assim dor e sofrimento. Fazendo uma analogia, era percebida como um prêmio pelos sofrimentos na terra. Essa fé nos dias atuais está cada vez mais afastada desses preceitos cultivados apenas pelas pessoas mais velhas.

Atualmente, percebe-se que o prolongamento da vida é motivado através de equipamentos muito sofisticados, onde um indivíduo acometido de uma patologia pode permanecer por anos, assim, auxiliado por máquina, retardando sua morte. A medicina, nesse caso específico, tinha papel de restabelecer a saúde. Com isso a família acreditava na religião e no poder da cura.

No estágio que inicia de negação e isolamento diante do quadro que se apresenta de um diagnóstico o paciente busca não compreender o que está acontecendo e, numa postura de negar sua condição, burla a verdade de forma a não aceitar um diagnóstico. Suas atitudes são de novos diagnósticos, pois busca resposta que anulem a primeira - no caso, a negação - e sufoquem uma angústia desnecessária. Quando da confirmação, novamente busca outra saída na esperança de uma nova interpretação.

Comumente a negação é uma defesa temporária, sendo logo substituída por uma aceitação parcial. A negação assumida nem sempre aumenta a tristeza, caso dure até o fim, o que, ainda, considero uma raridade (KÜBLER-ROSS, 1996, p. 26). 
Nesse momento o paciente, já um tanto sofrido pela busca de compreender e entender sua patologia, começa a substituir seu sentimento de negação pela raiva. Vários são os questionamentos do porque aconteceu uma fatalidade dessas, e se manter firme diante de um quadro agressivo da doença não é fácil. Uma vez acometido, sua postura para o enfrentamento - bem como seus familiares torna penoso o reconhecer-se doente, e muitas vezes o paciente não tem expectativas quanto à cura e passando a negligenciar a presença dos mesmos.

Quando dos momentos de rejeição, mesmo sendo o tratamento adequado para prolongá-lo da vida, o paciente reage com agressividade aos médicos, equipe de enfermagem e mesmo os familiares. No entanto esse tipo de comportamento para o paciente, na sua visão de ser doente, já não faz tanto sentido. Afinal, ele sabe que seu fim está próximo.

Outro estágio pelo qual o paciente vivencia é o da barganha. Neste, há um adiamento do sofrimento através do "bom comportamento", com o intuito de receber uma premiação. Por exemplo, um paciente em estado terminal deseja visitar um amigo. Então ele se comporta bem, toma todos os medicamentos e depois pede ao médico que o deixe ir ver o tal amigo. Na maioria das vezes, a equipe do hospital acaba cedendo, porém, o paciente não deixa de pedir novamente, se outra vez quiser visitar alguém. É a chamada "promessa implícita!". Diante da situação, ele faz a promessa de que esse é o último pedido, todavia nunca obedecerá. A maior parte das barganhas é feita com Deus, em segredo, e indica uma realização de atingir alguma meta imposta a ser cumprida.

Psicologicamente, as promessas podem estar associadas a uma culpa recôndita. Portanto, seria bom se as observações feitas por esses pacientes não fossem menosprezadas pela equipe hospitalar (KÜBLER-ROSS, 1996, p. 97).

Um estágio bastante conhecido principalmente quando o paciente encontra-se em fase terminal - é a depressão. Há dois tipos de depressão: a que o paciente geralmente reage, quando pensa em tudo o que fez ou deixou de fazer, pensa nas pessoas de que gosta ou não, pensa nos amigos e na família que tem que deixar, aumentando a sua tristeza e o seu sentimento de culpa; e a que o paciente tem de se submeter para se preparar para a morte. Este último tipo de depressão leva em consideração perdas iminente, ou seja, perdas imediatas, diferente do primeiro tipo que aborda perdas passadas.

Um pensamento animador seria o livre desabafo de algo que não sufocasse seu sentimento e deixasse fluir o que lhe ocorresse de discurso, assim, o paciente estivesse se preparando para a morte. Fosse encorajado a ver o lado bom das coisas, mas sim ouvido, gerando nele a vontade de se comunicar, falar abertamente o que sente e perceber que é ouvido. Ele necessita exteriorizar o seu sofrimento para que, desse modo, haja um alívio e certo agradecimento por parte dele.

\begin{abstract}
É esta a hora em que o paciente pede para rezar, em que começa a se ocupar com coisas que estão a sua frente e não com as que ficaram para trás. É a hora em que a interferência excessiva de visitantes que tentam animá-lo retarda sua preparação emocional, em vez de incentivá-la (KÜBLER-ROSS, 1996, p. 101-102).
\end{abstract}

Talvez se a equipe toda tivesse essa visão, ajudaria mais no apoio ao paciente neste estado. Considera-se no pensamento da autora que nesse contexto ainda fica uma lacuna no pensar uma interligação de pessoas que trabalham juntos, mas que cada um faz o seu trabalho e somente só. Contextualiza-se numa perspectiva de que se a equipe fosse mais integrada juntamente no apoio familiar, a aceitação do morrer seria mais bem compreendida, por assim dizer, a família estaria sendo apoiada na fase de ajudar o paciente à 
aceitação e assim sua angústia diminuiria.

\begin{abstract}
Deveriam saber que este tipo de depressão é necessário e benéfico, se o paciente tiver de morrer num estágio de aceitação e paz. Só os que conseguiram superar suas angústias e ansiedades são capazes de alcançar este estágio. Se esta angústia pudesse ser dividida com seus familiares, seria evitada muita angústia. (KÜBLERROSS, 1996, p. 102).
\end{abstract}

Por outro lado, aquela pessoa que foi acolhida, entendida, que recebeu ajuda para superar seu estado, bem como foi preparada para o que vier mais à frente, vai atingir o estágio da aceitação com maior abertura. Nele, não haverá mais raiva, nem depressão, considerando que se entende que ele já foi ouvido, já entendeu sua situação, e já não pode mais ir contra seu destino. "Todo o sentimento supõe-se que já fora externalizado. Então agora só apresenta expectativas. Não significa ser certo tipo de felicidade, mas uma fuga de sentimentos" (KÜBLER-ROSS, 1996, p.103).

Esse é um período em que se deve apoiar a família, sempre a compreendendo e ajudando no que precisar. Geralmente o paciente quer ficar só, sem conversar, o que deve ser respeitado. Há pacientes em que este tipo de estágio não ocorre, devido a não aceitação da doença. A maioria das pessoas pensa que este tipo de paciente pode realmente melhorar se lutar e resistir. Geralmente isso acontece pela própria não aceitação da família ou dos amigos, que o encorajam a lutar, pois desistir e aceitar contata-se duas ações covardes. Contudo, não se sabe ao certo se isso é o melhor para o paciente ou se o melhor seria deixá-lo partir.

Enfim, não deveríamos menosprezar que o paciente guarde uma tênue esperança de cura diante da morte iminente. [...] não está na natureza humana aceitar a morte sem deixar uma porta aberta para uma esperança qualquer. Portanto, não basta ouvir somente as comunicações verbais de nossos pacientes (KÜBLER-ROSS, 1996, p. 130)

Depois de todos esses estágios os quais o paciente enfrenta, a única coisa que resta direto no imaginário daquele paciente é a esperança. É ela que percorre intacto todo o caminho dele, desde a descoberta da doença até a sua morte. Mesmo os que aceitaram sua finitude, não perderam de forma alguma a esperança, seja na esfera espiritual, seja na esfera científica.

É essa esperança que vai sustentar todo o sofrimento sentido pelo paciente, bem como todo o tratamento realizado pela equipe técnica para o mesmo. Desse modo, ele pode até se submeter a "servir de cobaia", caso haja descoberto algum tipo de cura e, muitas vezes o procedimento até retarda a morte que antes era mais próxima, ampliando assim mais uma tentativa de sobrevida. Como afirma Kübler-Ross,

\begin{abstract}
Não importa o nome que tenha; descobrimos que todos os nosso pacientes conservaram essa sensação que serviu de conforto em ocasiões especialmente difíceis. [...]. Mantínhamos com eles uma esperança firme, que não lhes era imposta, quando finalmente desistiam sem desespero, mas num estágio de aceitação final (KÜBLER-ROSS, 1996, p. 153).
\end{abstract}

É importante notar que vários pacientes, através desse sentimento, conseguem se recuperar ou pelo menos adiar sua morte. O que acarreta em uma aceitação melhor, pois o indivíduo terá tempo para passar pelos estágios anteriores. Muito ajudaria se as pessoas conversassem mais sobre a morte e o morrer, como parte intrínseca da vida, do mesmo modo em que não temem ao falar no nascimento de um bebê (KÜBLER-ROSS, 1996, p. 154).

A contribuição da Psicologia para com o doente em fase terminal, no apoio emocional é de suma importância, visto que, sendo ele o profissional da escuta, saberá acolher a expressão das dores pelas quais passa o paciente, sejam elas 
em relação à doença, seja em relação a algo mal resolvido, sejam temores, planejamentos para o pós-morte ou outros. O Psicólogo também poderá ajudar a família, apoiando no lidar com o luto que ora se faz evidente, numa perspectiva de aceitação da finitude, como também o suporte da equipe de saúde a compreender a importância da fala do paciente nessa sua fase final, evitando assim, que o mesmo seja negligenciado em relação à escuta e apoiando em seus últimos momentos vivenciais.

A segunda qualidade da consulta psicológica é a sua permissividade em relação à expressão de sentimentos. O cliente, através da aceitação pelo psicólogo do que diz da completa ausência de qualquer atitude moralista ou judicativa, da atitude compreensão que impregna toda a entrevista, acaba por reconhecer que todos os sentimentos e atitudes podem se exprimir. Nenhuma atitude é demasiado agressiva, nenhum sentimento demasiado culpado ou vergonhoso para não ser expresso na relação. $\mathrm{O}$ ódio pelo pai, sentimentos de conflito devido aos impulsos sexuais, remorso por atos passados, repugnância em vir pedir ajuda, hostilidade e ressentimento para com o terapeuta, tudo isso pode se exprimir (ROGERS, 2005, p. 88).

A proximidade para com a morte pode trazer sofrimento psíquico para o paciente e seus familiares pelo fato de não se ter clareza do que ocorre após o término do ciclo vital. Tudo isso parece incerto e inseguro, por se encontrar numa situação de vulnerabilidade e em local insalubre, como hospitais. É um momento na fase de vida do paciente que abre uma nova etapa, ou seja, ele vai aprender e lidar com seus últimos momentos e o ambiente hospitalar torna-se um agravante para sua condição de permanecer ali até o fim de seus dias.

De acordo com Nietzsche,

Aquele que sofre profundamente, encerrado de alguma forma em seu sofrimento, lança um olhar gélido para fora sobre as coisas: todos esses pequenos encantamentos enganadores em que habitualmente se movem as coisas, quando são olhadas por alguém saudável, desaparecem para ele: ele permanece envolto em si, sem encanto e sem cor (NIETZSCHE, 2008, p. 113).
A morte, para a cultura ocidental, é vislumbrado como um fim. É como se houvesse uma completa perda de tudo que dissesse respeito à vida, uma quebra total dos laços parentais, de amizade, etc.. De forma que o assunto torna-se tão horroroso que se evita falar dele. Falar é como se atraísse a morte e, portanto, é melhor nem citá-la. Sendo assim, evita-se tratar do assunto e vão sendo criados conhecimentos superficiais em torno do caso. É certo que é o encerramento do ciclo vital. Porem, essa finitude terrena, que é tão certa, pode ser discutida e trabalhada para que os mitos se dissipem.

Alguns, absorvidos pelos sofrimentos, tomam atitudes positivas frente à vida, no sentido de se desfazer de preconceitos, pensar em reconciliação, valorizar coisas simples, etc...

Quando se contempla a finitude por conta de doenças, idade avançada ou perda dos amigos, ou em situações de grande perigo, muitas vezes vislumbra-se um olhar mais valorativo sobre a vida e questiona coisas, como: para que orgulho? Para que acúmulos? Isso, porém, é relativo, depende das subjetividades envolvidas. Quando a experiência é mesmo de morte, de finitude esperada, é necessário a pessoa ultrapassar todas as fases (negação, isolamento, raiva, barganha, depressão) até chegar à aceitação e assumir com tranquilidade a vivência. É o que Mitch nos explica da seguinte forma:

Tome qualquer emoção: amor por uma mulher, sofrimento por um ente querido, ou isso por que estou passando, medo e dor causados por uma doença mortal. Se você bloquear suas emoções, se não se permitir ir fundo nelas, nunca conseguirá se desapegar estará muito ocupado em ter medo da dor, medo do sofrimento. Terá medo da vulnerabilidade que o amor traz com ele. - Mas atirando-se a essas emoções, mergulhando nelas até o fim, até se afogar nelas, você as experimenta em toda a plenitude, completamente. Saberá o que é dor. Saberá o que é o amor. Saberá o que é sofrimento. Só então poderá dizer, "muito bem, experimentei essa emoção. Eu a reconheço. Agora preciso me desapegar dela por um momento" (MITCH, 1997, p. 103). 
As doenças alteram a vida familiar, podem aparecer ressentimentos por conta das novas adaptações, como a mulher assumir negócios, dívidas, etc... Porém, é importante que as pessoas prossigam com suas vidas, que saibam cuidar de si e não se escravizem à rotina que se instala. Esse estado de reconhecimento da fragilidade de saúde permite uma elaboração diante do processo de sofrimento psíquico em abalo emocional, cabendo ao individuo vivenciar sua dor, pois só a ele pertence e somente ele pode significar para dar sentido a seu momento.

$$
\text { É muito importante a presença dos }
$$
familiares quando o paciente está enfermo, visto que o amor, o zelo, o cuidado, revigora as forças do paciente e torna suportável a experiência do morrer. Os parentes e amigos costumam olhar a pessoa e não somente a doença. Diferentemente de muitos profissionais, que deixam de enxergar a pessoa que está doente e veem somente a sua enfermidade. Neste sentido, Klüber destaca:

Se não levarmos devidamente em conta a família do paciente em fase terminal, não poderemos ajudá-lo com eficácia. No período da doença, os familiares desempenham papel preponderante, e suas reações muito contribuem para a própria reação do paciente (KLÜBER-ROSS, 1996, p. 171).

O desamparo dos pacientes em fase terminal nos hospitais, bem como, de seus familiares conduz a reflexão sobre a humanização. O trabalho técnico e o convívio constante com dores e perdas naturalizam os acontecimentos, tal como ocorre com a percepção perante aqueles que dormem nas ruas e pede o pão, quase ninguém mais se angustia. Ocorre uma habituação com aquela realidade, de forma que não se tem sobre ela visão crítica, nem tampouco humanizada.

A situação dessas pessoas em estado de hospitalização passa a ser determinante de muitas situações que serão consideradas invasivas e abusivas na medida em que não respeitam os limites e imposições da pessoa hospitalizada, nesse contexto há um sofrimento maior e assim mais difíceis de superação de sua condição de saúde (CAMON, 2010, p. 107).

As mortes por suicídio, por crimes, por problemas cardíacos, por doenças avassaladoras pegam as pessoas de surpresa e deixam uma dor muito mais profunda, como se a morte não tivesse dado tempo de se reconciliar com a pessoa que partiu.

Muitas exortações existem no sentido de que a vida deve ser vivida em plenitude todos os dias. Há quem viva do passado, há quem viva para o futuro, mas o certo é que o presente é o menos valorizado. E quando se fala que alguém vive o presente, é como se fosse um desperdiçador de tempo, alguém que pode ser pego de surpresa. Há algumas pessoas que escolhem ser úteis até os seus dias finais, contribuindo assim com a humanidade por deixar um legado.

\begin{abstract}
- Como podemos nos preparar para morrer? - Perguntei. - Fazendo como os budistas. No começo de cada dia ter um passarinho pousado no ombro, que pergunta: "É hoje que vou morrer? Estou preparado? Estou fazendo tudo que preciso fazer? Estou sendo a pessoa que quero ser? [...] A verdade Mitch, é que, quando se aprende a morrer, aprende-se a viver (MITCH, 1998, p. 84- 85).
\end{abstract}

\section{REPRESENTAÇÃO DA MORTE DE JESUS}

Na passagem da Bíblia Sagrada em Mateus 26 (Versículos 38-39) nos fala que: "Retirou-se Jesus com eles para um lugar chamado Getsêmani e disse-lhes: 'Assentais-vos aqui, enquanto eu vou orar'. E, tomando Pedro e os dois filhos de Zebedeu, começou a entristecer-se e a angustiar-se. Disse-lhes então: 'Minha alma está triste até a morte. Ficai aqui comigo'. Adiantou-se um pouco 
e, prostrando-se com a face por terra, assim rezou: 'Meu Pai, se é possível afasta de mim este cálice! Todavia não se faça o que eu quero, mas sim o que tu queres",.

Nesse contexto, segundo a escritura sagrada, todo o sofrimento se faz pela angústia de entrar em contato com a finitude. Jesus temeu em pensar sobre a morte e o morrer, ficando nítida a sua percepção da hora final. Sendo o Filho de Deus e Salvador do mundo, numa perspectiva cristã, também teve que experenciar sobre o crucial momento de sua finitude terrena, cabendo assim uma luta interna sobre a possibilidade de adiar, afastar, barganhar sobre a morte, mas se fez o rompimento da sua vida. A morte é o significado do desencarne do corpo e a ideia é válida sim, entretanto pode-se confirmar pelas escrituras da Bíblia Sagrada.

Em Lucas 23, (Versículo 44-46), diz que: "Era quase à hora sexta e em toda a terra houve trevas até a hora nona (pelo meio dia)". Escureceuse e o sol e o véu do tempo rasgou-se pelo meio. Jesus então deu um grande brado e disse: 'Pai, nas tuas mãos entrego o meu espírito'. E, dizendo isso expirou. Percebe-se que nesse contexto foi explicitada e chegada à morte. No cristianismo, e sendo o maior protagonista da história da humanidade também sofreu, temeu, passando pela dor da morte anunciada desde seu nascimento, conforme as escrituras sagradas afirmam.

Infere-se que os fatos acontecidos ao longo da história da humanidade, dão conotação para o fenômeno da passagem a um plano superior que é a morte e o morrer, mas que não se deixou de suscitar sobre o acontecido. Ao longo de 2014 anos D.C, o morrer mudou seu contexto pelo fato em si, mas os aspectos da perda ainda são arraigados pelos familiares, culturas e também aos sentimentos pelos entes queridos. Ainda são e estão presentes aspectos da condição da falta do ser humano, sua presença na lembrança perdurará nas pessoas as quais pertenceram. Naquela época, o significado da morte era sinal de luto e respeito pela ausência do falecido, cabendo à família chorar por longos períodos a perda do indivíduo.

\section{RESULTADOS E DISCURSSÕES}

Nesse contexto se faz pertinente um questionamento: por que estudar a morte? Notadamente pela falta de pesquisa no assunto, e pelo interesse científico que representa no cotidiano de todo ser vivente. O evoluir do ser humano é contextualizado de forma prática e sistêmica. Não se pensa na finitude, ao contrário, planeja-se, constrói-se em perspectivas futuras como continuidade de vida. No entanto, esse fragmento de fim de vida existe e não é falado.

Com elementos mais significativos elencados ao longo da pesquisa, percebeu-se que ainda há um misto de receio de perguntar ou se falar abertamente, pois a ideia que as pessoas têm é a plenitude da vida, planejamentos, tempo para programar o futuro e tantos outros fatores. O tema é bastante antigo, e mesmo em séculos de evolução da humanidade e da tecnologia, futuro de descobertas para tantos males da vida, ainda é tabu falar sobre morte.

Percebe-se que o comportamento das pessoas causa medo, angústia e choro, pois afinal, é uma vida que se foi e agora o legado só viverá através das lembranças que foram deixadas. $\mathrm{Na}$ representação social, Jordele, 2001 reporta que tem cunho cultural para cada sociedade e interfere na concepção de cada indivíduo, compreendendo assim, que se configuram de formas diversificadas a partir da relação que o indivíduo tem com sua visão de mundo.

Como tantos outros poderíamos fazê-lo, que as representações sociais são fenômenos complexos que sempre ativados e em ação na vida social. Em sua riqueza como fenômeno, descobrimos diversos elementos (alguns, às 
vezes, estudados de modo isolado): informativos, cognitivos, ideológicos, normativos, crenças, valores, atitudes, opiniões, imagens, etc. Contudo, estes elementos são organizados sempre sob a aparência de um saber que diz algo sobre o estado da realidade (JORDELE, 2001, p. 21).

Nesse contexto, a representação social segundo Jordele 2001, aponta que é abordada como produto e processo de uma atividade apropriada da realidade exterior ao pensamento e de elaboração psicológica e social. Para a pesquisa a temática atual, a morte é tão comum quanto o nascer. Acontecem muitas vezes e inesperadamente e assim precipita a morte, falando de eventos ocorridos por fatalidades em que muitas vidas são ceifadas pelos desastres, assassinatos, chacinas e assaltos seguidos de morte. É um fato que não está na ordem da normalidade, mas que se evidenciam enormemente na atualidade, suscitando a todo o momento um questionamento sobre o fenômeno da morte.

Não é comum saber sobre o rompimento da vida por morte precoce. Isso faz nova leitura sobre que fatores estão sendo cuidados com a vida, ou seja, uma pessoa em plena capacidade de juventude ser assassinada por um fato banal como uma discordância de pensamento, por exemplo, é real e acontece muito durante todo dia em diferentes centros urbanos e contextos sociais. A vida de uma pessoa pode ser interrompida tão abruptamente por um fator qualquer como um assassinato? É uma reflexão que se contextualiza nos dias atuais, apesar de toda plenitude de juventude e planos futuros, a modernidade trouxe para as pessoas avanços, porém a morte também é suscitada e não se fala sobre.

$\mathrm{Na}$ passagem da Bíblia Sagrada (Mateus 26 versículos 38,39) percebe-se que foi explicitada a presença da morte e que não havia como escapar desse momento crucial, principalmente em sendo Jesus, o maior protagonista da história da humanidade, também sofreu e passou pelo fenômeno a ele imposto conforme as escrituras sagradas afirmam.

Elencando subsídios que estão no campo da representatividade sobre a morte, percebe-se que é um tema bastante antigo, ou seja, morrer faz parte da vida tanto quanto qualquer outra etapa do desenvolvimento humano.

A representação da morte foi contextualizada e marcada pela passagem do momento crucial da morte de Jesus na cruz, representando assim o sinal que, definitivamente, na história da humanidade ficasse marcado. Fotos históricos ao longo da existência humana são notificados diariamente, sobretudo à forma dessa representação mudou o contexto, mas as mesmas essências permanecem ao longo dos séculos.

A representação da morte mudou ao longo da história, notadamente pela vida cotidiana de grandes centros urbanos, onde os índices de mortes e assassinatos sobem nas estatísticas do país. É um contexto que não se vê, entretanto, acontece diariamente e muitas vezes nem são notificados, cabendo somente às famílias que sentem a separação de seu ente querido. Tais fenômenos também fazem parte da representação sobre pensar a morte e o morrer.

O paralelo que se constrói nesse estudo sobre a representação da morte e o morrer, é despertar para algo que é certo: cedo ou não todos passarão pelo momento da morte. A morte é a última fase de evolução do ciclo da vida, ao mesmo tempo em que a vida é vista como aspecto de longevidade. Contudo, não se tem garantia alguma de extensão da mesma, basta que se adoeça para que um pensamento surja como o fenômeno da morte. É pensar que somos seres finitos e ver que o fim é certo.

\section{FENÔMENOS DOS RITOS FUNERAIS ATUAL}


$\mathrm{Na}$ atualidade são inúmeros os recursos utilizados para o sepultamento, ornamentação, assistência funerária de entes queridos. São empresas que atuam na perspectiva da morte, mas que dão sua contribuição de atender famílias nesse momento. Em parte do país criou-se uma rede de estabelecimentos que são especializados para esse fim. São funerárias especializadas que fazem desde o recolhimento do corpo em unidades hospitalares, Serviços de Verificação de Óbitos - SVO (unidade responsável para dar um parecer sobre o falecimento do indivíduo). São eles que levam o translado até as residências quando as famílias querem seus mortos para velório domiciliar até um centro de velório das referidas funerárias.

$\mathrm{O}$ atendimento é tão especializado que um corpo pode passar dias para o sepultamento, contando para isso com a técnica da Tanatopraxia que tem por finalidade desinfetar e retardar o processo de decomposição dos corpos, cuja prevenção é para evitar o extravasamento de líquidos e odores como posteriores alterações anatômicos. Essa técnica impede o aparecimento de aspectos como a rigidez cadavérica e escurecimento da pele, permitindo assim a preservação das características quando ainda em vida.

Para que todo o ritual fúnebre seja ofertado aos associados é necessária uma proposta de um contrato social onde o cliente conta com um plano mensal em valores estabelecidos com padrões de qualidade. Ou seja, para cada plano haverá uma distinção de preços. A empresa ainda oferece ao cliente uma comodidade de veículos, pessoal treinado para o ambiente onde será o velório e serviço de acompanhamento até o cemitério para o momento final. Se o cliente optar pelo centro de velório, há espaço de amparo à família, constituindo assim um espaço de acolhimento para receberem pessoas que visitaram o morto, permitindo até apartamento para descanso de quem assim desejar.

A equipe de colaboradores é treinada para situação de urgência e emergência, havendo uma ambulância a serviço para aquele funeral - caso seja solicitado pela família. Notadamente a funerária se responsabiliza por toda assistência que antes era protagonizada pelo familiar, ou seja, uma ideia que se evidenciou para a modernidade e passou ao longo do tempo pela aceitação do público. Porém não foi aceito de imediato, afinal, alguém veio vender urna funéria, ou seja, o planejamento do ritual funerário deu subsídio para um negócio promissor e dessa forma conquistou o objetivo daquele empresário empreendedor. Assim sua ideia há anos fora ideal para um momento tão difícil e atualmente é muito buscada para os rituais funerários da separação do ente querido.

\section{Caracterizações dos rituais fúnebres}

A caracterização do ambiente fúnebre atual é um aparato estruturante e que gera um contingente de colaboradores para esse fim, notadamente pelo aspecto do conforto proporcionado às famílias que são associados das funerárias. Existe uma norma que é válida para todos que adquirem os serviços: há um só tratamento para cada serviço contratado.

Atualmente com esses recursos de deixar todo o funeral para uma empresa especializada, tornou-se uma prática objetiva e geradora de soluções para as famílias. O serviço é direcionado especificamente no cuidar dos familiares, ou seja, há pessoas que lideram no sentido de resolver qualquer entrave para que o sepultamento ocorra sem que um familiar seja encarregado desse tramite. Nesse sentido, evita-se o sofrimento do familiar em lidar para que o sepultamento ocorra sem impedimentos legais. No espaço destinado a velórios existem componentes exclusivos para tal 
fim. Compreendendo a condição de finitude, é um negócio promissor, vendo pela genialidade do seu protagonista.

Em relação ao tempo e espaço de atendimento a família do falecido, a urgência pela assistência é compreendida como normal e eficiente, embora o sentido da morte e seu funeral ainda se perpetuam até os dias atuais. A ideia de enterrar os mortos continua como antes, quando do desejo do falecido, poderá ocorrer à cremação, fato que algumas famílias utilizam com menos frequência.

\section{Percepções do comportamento dos familiares em relação à separação pela morte}

Em observação durante a pesquisa foram elencados vários significados pela postura de comportamentos. E, é importante contextualizar que os familiares são acometidos pelo vivenciar a percepção da condição expressa pelo fato, ou seja, o fenômeno em si.

Numa perspectiva de conceituar a Fenomenologia dentro do campo da Psicologia, para ter uma melhor compreensão do tema, recorremos à Muller-Granzzoto. Ele afirma que a Fenomenologia é um método em que o homem se utiliza para conhecer o mundo, ou seja, há uma essência subjetiva sociável no qual define três pilares que move o ser no mundo. Primeiro o que é o mundo para o sujeito, segundo o que é o ser e o terceiro o que existe no mundo. Nisso há uma relação do ser que é imutável, habitando ai a essência do ser, e essa munda muda. (MULLERGRANZZOTO, 2007)

No caso do fenômeno da morte que se estudou nessa pesquisa, é o sentido da Fenomenologia em sua abordagem aponta naquilo que é aparente, ou seja, no contexto da transformação ao retorno das coisas mesmas. Nesse contexto, sempre se volta a estudar a teoria fenomenológica para dar cientificidade à pesquisa. Bruns, 2005, faz aporte que na visão de Husserl a redução fenomenológica que é a atitude frente ao mundo de buscar compreender as experiências abrindo mão de seus a priores ou preconceitos para que ocorra o fenômeno. Há assim uma possibilidade do método como resposta o campo da ciência do conhecimento, a fenomenologia é o caminho/método que tem por meta a constituição da ciência da essência do conhecimento ou doutrina universal das essências.

\begin{abstract}
A fenomenologia proporcionou à Psicologia uma nova postura para inquirir os fenômenos psicológicos: a de não se ater somente ao estudo de comportamentos observáveis e controláveis, mas procurar interrogar as experiências vividas e os significados que o sujeito lhes atribui, ou seja, o de não priorizar o objeto e/ou sujeito, mas centrar-se na relação sujeito-objeto-mundo. (BRUNS, 2005, p. 60-61).
\end{abstract}

Compreender o fenômeno como manifestação é tornar para o indivíduo consciência de si mesmo, assim o sujeito torna-se consciente de que é um ser finito. Essa redução fenomenológica é um método do pensamento que se busca ver as coisas mesmas munidas de um sentido que se apresenta na relação de morte. É necessário suspender qualquer preconceito para a percepção do fenômeno. Assim, o objeto da relação é a consciência que se faz da coisa. No caso do pensar a morte e o morrer está na relação que o sujeito tem diante do fenômeno como algo que se estabelece e assim poderá haver maior aceitação dessa condição de finitude.

As posturas adotadas por pessoas ainda é de não saber lidar com a morte, ou seja, não há uma aceitação formal sobre a mesma. Mesmo porque, não se fala sobre o fato, se oculta e não é explorado.

No que se refere a dar notícia de falecimento de alguém, a reação primeira é de surpresa, mesmo sabendo que há uma patologia 
terminal, ou mais surpreendentemente por uma fatalidade ocasionada pelo rompimento da vida, ou seja, não se aceita a morte. O comportamento é de dor visível, notadamente pelo choro, apego ao corpo da pessoa exposta ao velório e até pela condição de retardar a saída para o sepultamento. Há uma reação de resistência por alguns, e talvez até de culpa, quando por verbalização do familiar, ou seja, ele fala abertamente da dor de não ter dito ou feito o que planejara, pois a morte interrompeu o assunto que estava pendente.

Para a pesquisadora o que mais chamou atenção foi o romper da relação afetiva, ou seja, a vida é vista em plenitude, é como se todo dia um estivesse trazendo consigo um amanhã e os assuntos podem ser explorados ou discutidos em outro momento. Na perspectiva da morte, não há o amanhã, haverá o pressuposto do rompimento repentino e assim ficando uma pendência a ser fechada para quem fica. Essa observação ficou marcada por uma das visitas durante um velório; para o outro que ficou não há como reverter à situação não resolvida e isso se caracteriza como algo que não se fecha jamais.

\section{Luto afetivo e demonstrativo pessoal}

Em tempos de eternas mudanças pelos avanços tecnológicos e até pela mudança das percepções acerca do luto propriamente dito, houve significativas posturas ao longo das gerações. $\mathrm{Na}$ antiguidade, contextualizando mesmo a época da morte de Jesus, os rituais do luto eram visivelmente percebidos, pois cercava desde o recolhimento pessoal e familiar pela ausência do ente, como também pelo comportamento do familiar pela vestimenta.

As pessoas vestiam-se de preto, significando a perda, e desse modo passavam meses de luto. Porém, há de se destacar a diferenciação entre as diversas pessoas, ou seja, os homens vestiam diferentes das mulheres. Com o passar do tempo, vestir-se para demonstrar luto, torna-se obsoleto o preto como cor nas vestimentas das pessoas, embora ainda pessoas idosas pratiquem essa forma representação. Havia o respeito pela ausência e também o tempo do luto significava a condição para aceitação da partida.

Mesmo as crianças de épocas atrás também eram vestidas pelo luto, sendo a cor preta, ficando assim demonstrado o sentimento de separação entre a vida e a morte, no caso seus familiares tomavam essa atitude. Percebe-se que, ao longo de uma trajetória de séculos, ficaram marcados comportamentos de informação sobre a morte, ou seja, aquilo denunciava o respeito à dor da família sinalizado pelo preto em seu corpo, principalmente as mulheres viúvas, que se vestiam para o resto da vida, e no dedo esquerdo a aliança do esposo.

No contexto atual, é obsoleta esta prática, ou seja, o luto, por exemplo, como opção de vestimenta preta, tornou-se desnecessário. Há nessa interface conotações extremas, ou seja, ao longo do desenvolvimento e ascensão da humanidade, os valores mudaram completamente. Alguns remanescentes praticam o ritual e perpetuam os rituais de antigamente.

O luto afetivo muitas vezes é substituído por artifícios de acomodação e praticidade dos familiares, pois existem pessoas treinadas para tal acontecimento. Há hoje quem chore por um morto sem que tenha vínculo nenhum. Embora os serviços funerários tenham em seu quadro de colaboradores pessoas treinadas para sofrer pela perda do falecido. Nesse avanço do tempo, as facilidades que contribuem para o momento da separação até o sepultamento sempre haverá alguém para exercer o papel de familiar. Questiona-se sobre os avanços tecnológicos, mas onde fica a dor pela perda da morte? 


\section{CONSIDERAÇÕES FINAIS}

O questionamento e reflexão sobre a morte ainda é pouco abordado nas literaturas. Mas, sua importância é extrema para a humanidade, tanto para discussão, como também para as mais diversas áreas. A ideia da vida é constante, sobretudo quando se goza de boa saúde, e em nenhuma hipótese deve-se pensar na morte. Abordar o tema suscita um parêntese a se pensar. E, como um ciclo que se fecha, a morte é a finitude de todo os ciclos durante o desenvolvimento humano.

Percebe-se a necessidade de incutir discussões a cerca da temática. E nesse contexto, as instituições de educação entram como norteadores em ofertar disciplinas para expor o significado da finitude. Promover pesquisas em áreas educacionais, coletivas e sociais em pensar perspectivas a sugerir algo dentro da normalidade da vida.

Pensar uma prática diferente ajuda a dar oportunidades em pesquisas, pois seria uma forma de dar conhecimento de fatos considerados como a finitude, reduzir preconceitos e oportunizar reflexões mais objetivas a cerca do tema. Evidentemente, respeitando a dor de alguém pela perda e seu luto, mas pensando sempre que é fato notório que muitas posturas podem ser repensadas e capacitar profissionais para mediar essa relação da perda em uma visão mais realista da finitude.

Repensar a vida como um ciclo evolutivo que promove e possibilitam mudanças, alegrias, comportamentos para prolongar essa condição, também pode abrir um parêntese para se perceber o outro lado da vida, ou seja, a morte é só mais uma condição de finitude. A lembrança sempre ficará na vivencia de outras pessoas, a existência é contextualizada a planos, mas que pode ser rompido a qualquer momento, seja por um adoecimento e que fatalmente aconteça o falecimento, ou por anos a fio na luta pelo restabelecimento.

Concluindo o estudo, percebe-se que os rituais funerários evoluíram e deram ao seguimento mercadológico cunho lucrativo, em um bem estar às famílias que perderam seu ente, como também pelo avanço da modernidade ao longo da história da humanidade. Considera-se que trouxe comodidade e auxílio num momento delicado.

Alguém ousou e abarcou esse momento da condição de finitude. É percebido como um cenário inovador e que fará muito ainda pelo serviço prestado, em virtude de séculos. Hoje estamos mais contemporâneos e com maior aceitação da morte no sentido de amparo do funeral.

Acredita-se que os objetivos foram contemplados ao pensar num tema tão complexo e pouco estudado. Contudo, o desafio está lançado e muito ainda deve-se contextualizar sobre a morte, contar a história de vida do homem na perspectiva do fim da matéria. Que novas posturas emerjam na cultura do pensar a finitude.

$\mathrm{O}$ questionamento da pesquisa objetivou um pensamento pouco contextualizado, mas que todas as pessoas no cenário mundial irão ter seu dia de morte. Assim, morrer é necessário porque é tão antiga quanto à evolução do ciclo vital. A ideia de conversar mais abertamente com pessoas, profissionais e pacientes que ora estão passando pelo momento de seu fim terrestre, faz-se necessário por manter um olhar sobre a vida.

\section{REFERÊNCIAS}

ALBOM, Mitch - A Última Grande Lição - O sentido da Vida - Tradução José J. Veiga, Rio de Janeiro, 1998, Sextante.

BÍBLIA Sagrada. A.T. Lucas. Ed. São Paulo: editora Ave-Maria, 1982. Cap. 23(V. 44-46), pag. 1381.

Mateus. Ed. São Paulo: editora AveMaria, 1982. Cap. 26 (V. 38-39), pag. 1318.

BRUNS, Maria Alves de Toledo. A Redução Fenomenológica em Husserl e a possibilidade de 
superar impasses entre a subjetividade e a objetividade. In: HOLANDA, Adriano Furtado. Psicologia e pesquisa fenomenológica: reflexões e perspectivas. São Paulo: Ômega Editora, 2005.

CRUZ NETO, Otávio. O trabalho de campo como descoberta e criação. In: DESLANDE, Suely Ferreira. Pesquisa Social: Teoria, método e criatividade. Petrópolis, RJ. Vozes, 1994.

CAMON, Valdemar Augusto Angerami. Psicologia e Religião. Editora Cengage Learning. São Paulo. 2008.

CAMON, Valdemar Augusto Angerami. (org). Psicologia Hospitalar. Teoria e Prática. $2^{\mathrm{a}}$ edição. São Paulo. Editora Cengage Learning. 2010.

COELHO, Francisco José Figueiredo. FALCÃO, Eliana Brígida Morais. Ensino científico e representações sociais de morte humana. Artigo Científico. Acesso em 19/04/2011.

CRUZ NETO, Otávio. O trabalho de campo como descoberta e criação. In: DESLANDE, Suely Ferreira. Pesquisa Social: Teoria, método e criatividade. Petrópolis, RJ. Vozes, 1994.

JORDELE, Denise. As representações sociais: um domínio em expansão. In: As representações sociais: Rio de Janeiro. UERJ, 2001.

MULLER-GRANZOTTO, Marcos J. MULLERGRANZOTTO Rosane L. Fenomenologia e Gestalt-terapia. São Paulo: Summus, 2007.

NIETZCHE, Friedrich. Aurora. $2^{\text {a }}$ Edição. Editora Escala. São Paulo, 1998.

ROGERS, Carl. R. Psicoterapia e Consulta

Psicológica. $3^{\text {a }}$ Edição. Editora Martins Fontes. São Paulo, 2005.

ROSS, Elisabeth Kübler. Sobre a Morte e o Morrer. Editora Martins Fontes. São Paulo 1996.

ROSS, Elisabeth Kübler. A Atuação do Psicólogo Diante De Crianças Hospitalizadas Em Iminência De Morte. Sobre a Morte e o Morrer. 2000.

Disponível em:

<http://www.espacopsicanalitico.psc.br/artigos_1.ht ml. Acesso em 30/05/2011. 